gravity and cellulose content. Dr. Perry discussed in some detail the result of progeny tests and the surveys of variation in wood density to be found in the forests. These two talks were of great interest and there was considerable discussion of the results in relation to the forests and industry in Canada.

In the afternoon Mr. A. R. C. Jones of Macdonald College conducted the members and guests on a most informative tour of the Morgan Arboretum where examples of farm woodlot management were seen, together with a wide selection of native and exotic trees and shrubs.

At the conclusion of the meeting, many of the members went on to the International Congress of Genetics in Montreal.

It should be pointed out that the proceedings of the Committee on Tree Breeding in Canada are published for limited distribution. Part I which includes the minutes is distributed to members only, while Part II, containing the progress reports and papers, is distributed to persons and organizations actively engaged in tree breeding outside of Canada.

\title{
DOES MAGNIFICATION IMPROVE MEASUREMENTS OF STAND HEIGHTS ON AERIAL PHOTOGRAPHS?'
}

\section{By David A. Bernstein}

The measurement of tree or stand heights is an important use of aerial photographs in forestry. Foresters are constantly seeking new ways to better their measurements. One possible method of improving height-measurement accuracy is by enlarging the photo image. This can be done by increasing the scale of the photography, enlarging the prints, or increasing the magnifying power of the stereoscope. Past work on the effect of photo scale has generally indicated that increased scale does not significantly improve height-measurement accuracy (1) (2) (3) (4) (5) (6). Similarly, print enlargement has not been effective (1). The possibilities of magnification have not been given much attention.

A study to determine the effect of magnification on the accuracy of height measurements was recently carried out by the U.S. Forest Service at Portland, Oregon. This study was based on the comparison of photo and field measurements of stand height on each of thirty-one one-fifth-acre plots in even-aged Douglas fir type. Stand height was defined as the average height of dominant and codominant trees. Field measurement of stand height ranged from 40 feet to 270 feet with an average of 112 feet. Stand height for each plot was estimated on the ground by measuring the height of three or more dominant and codominant trees with chain and Abney, and using these trees as a guide for the occular estimation of the remaining dominant and codominant trees on the plot.

\footnotetext{
${ }^{3}$ A contribution of Photogrammetry News, one of a series of reports by a committee under the chairmanship of Mr. J. R. Collins, Forestal, Forestry and Engineering International limited. ${ }^{9}$ Forester, Division of Timber Management, Region 6, Forest Service, U.S. Department of Agriculture.
} 
Three different powers of magnification were used for making height measurements from the photographs. An Abrams height finder, coupled with a pocket stereoscope, was used for approximately 2-power readings. An Old Delft scanning stereoscope was used in combination with a parallax bar for for 1.5-power and 4.5-power readings. The photographs were taken on panchromatic film at 1:12,000 scale with a 12-inch focal length camera. Four interpreters, all with several years' experience in forest photo interpretation, estimated stand height with each magnification power and on each of thirtyone plots.

The difference between each photo estimate and corresponding field estimate was considered a height-measurement error. Variation among these errors for a particular interpreter and magnification was used as the best indication of height measurement accuracy because it expresses the consistency of the measurement. Size of the average error was not considered in this study because adjustments can easily be made in most applications of stand height measurements.

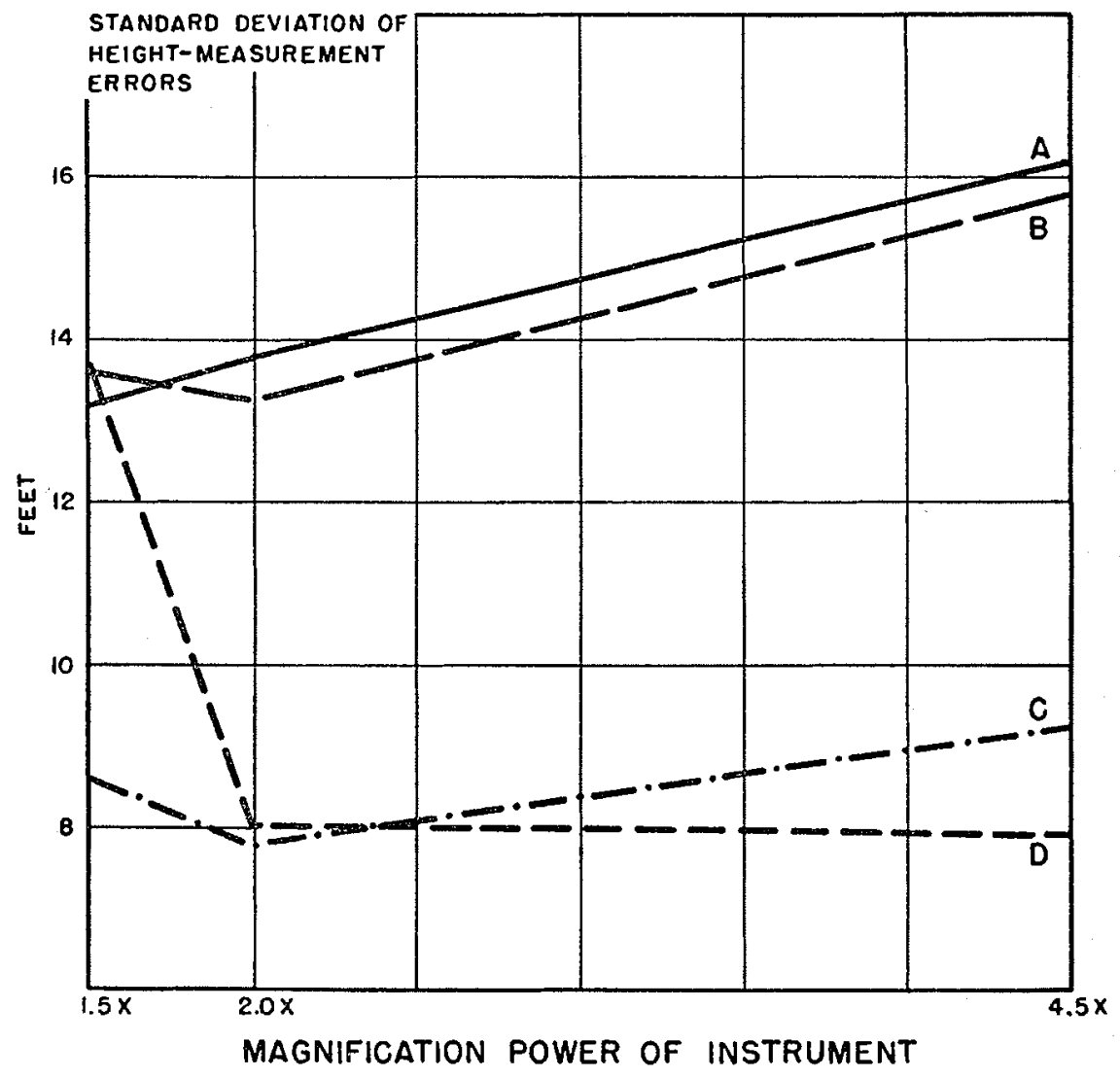


The results of the analysis on the height measurement errors are shown in the accompanying graph. Here, standard deviation (square root of variance) is used as an index to the variation in height measurement errors.

The graph indicates that in general the 2-power gives best results and 4.5power poorest. However, the study has produced no clear-cut evidence that the power of magnification has any relationship to the standard deviation of heightmeasurement errors. Three of the four interpreters ( $A, B$ and $C$ ) show no significant difference in the standard deviation of the height-measurement errors between various powers of magnification. One interpreter (D) did show a significant difference, having markedly poorer results with the 1.5-power. The presence or absence of significant differences was established by a test for homogeneity of variance (7).

An interesting observation is that all interpreters expressed more in height readings made with the 4.5-power than with the other two powers. However, this confidence was not borne out by the results. Similarly, all interpreters felt less confidence in the 1.5-power; yet in only one case did the standard deviation of the height-measurement error increase.

The results also show obvious differences among interpreters. Two interpreters, A and B, had almost identical results. Interpreter C had significantly lower variation, while interpreter $D$ fluctuated between the two levels.

This study tends to confirm other studies in image enlargement. Along with increased scale and print enlargement, magnification doesn't seem to be a promising way to improve height measurements.

1. ALLISON, GEORGE W. 1956. The accuracy of tree height measurements on various qualities of aerial photographs. Forestry Chronicle 32:444-450.

2. ANDREWS, G. S. 1936. Tree heights from air photographs by simple parallax measurements. Forestry Chronicle 12:152-197.

3. BATEMAN, A. R. 1952. A test of aerial photography for forest inventory purposes in the Tennessee Valley. TVA For. Invest. Branch Rep. No. 205-52.

4. JOHNSON, EVERT W. 1958. Effect of photographic scale on precision of individual tree-height measurement. Photogrammetric Engineering 24:142-152.

5. LOSEE, S. T. B. 1953. Timber estimates from large scale photographs. Photogrammetric Engineering 19:752-762.

6. POPE, ROBERT B. 1957. The effect of photo scale on the accuracy of forestry measurements. Photogrammetric Engineering 23:869-873.

7. SNEDECOR, GEORGE W. 1956. Statistical methods, Fifth Edition, The Iowa State College Press.

\section{NORMAN THAIN ENGELHARDT}

We deeply regret to report that on November 1, 1958, Norman Thain Engelhardt, 38, passed away in Victoria, B.C. Norm was engaged by the Forest Biology Laboratory as a Student Assistant during 1949 and 1950 and joined the permanent staff of the Laboratory in 1951, following graduation in Forestry from the University of British Columbia. He was granted a Master of Science Degree in Forest Pathology from Oregon State College in 1956. 